\title{
CALYPTOCEPHALA PARALUTEA SP.N. E DESCRIÇÃO DA LARYA E PUPA (COLEOPTERA, CHRYSOMELIDAE, CASSIDINAE) ${ }^{1}$
}

\author{
Zundir José Buzzi ${ }^{2}$ \\ Rosina D. Miyazaki ${ }^{3}$
}

\begin{abstract}
CALYPTOCEPHALA PARALUTEA, SP.N. AND DESCRIPTION OF THE LARVA AND PUPAE (COLEOPTERA, CHRYSOMELIDAE, CASSIDINAE). Adult, larva and pupa of Calyptocephala paralutea, a new species of Cassidinae, Spilophorini (Coleoptera, Chrysomelidae), from Porto Platon, Amapá, Brazil, is described.

KEY WORDS. Calyptocephala paralutea, sp.n., Chrysomelidae, biology
\end{abstract}

Em fins de 1984, recebemos do Sr. J.I. Lacerda Moura algumas larvas, pupas e adultos de uma espécie do gênero Calyptocephala Chevrolat, 1837, (Chrysomelidae, Cassidinae), fixadas em álcool $70 \%$, provenientes de Porto Platon, Amapá. Pela comparação com diapositivos das espécies de Calyptocephala do "The Natural History Museum", Londres, Inglaterra, tirados pelo Dr. Pe. Jesus Santiago Moure, concluímos tratar-se de uma espécie nova, identificada erroneamente como C. brevicomis no trabalho de Moura, 1985.

Calyptocephala, juntamente com o gênero Spilophora Boheman, 1850, caracterizados por SPAETH (1937), constituem a tribo Spilophorini (HINCKS, 1952). Do gênero Calyptocephala são conhecidas 11 espécies, segundo BLACKWELDER (1946) e em relação às formas imaturas nada consta na literatura.

\section{Calyptocephala paralutea, sp.n.}

Figs 1 e 2

Calyptocephala brevicornis; Moura, 1985: 37 (nec Boheman, 1850).

ADULTO

Aproximadamente 1,5 vezes mais longo que sua maior largura $(8,33 \mathrm{x}$ $5,67 \mathrm{~mm}$ ) (os três parátipos têm comprimento médio igual a $6,57 \times 4,98 \mathrm{~mm}$ de largura); de perfil (Fig. 4), aplanado ventralmente e no lado dorsal, elevando-se suavemente até próximo ao meio e posteriormente, inclinando-se fracamente para trás, mais fortemente próximo ao ápice; de coloração geral amarelo-parda.

1) Contribuição número 745 do Departamento de Zoologia, Universidade Federa do Paraná.

2) Departamento de Zoologia, Universidade Feral do Paraná, Caixa Postal 19020, 81531-970 Curitiba, Paraná, Brasil. Bolsista do CNPq.

3) Curso de Pós-graduação em Entomologia. Doutorado. Bolsista do CNPq. 
Antenas pretas, exceto o escapo e o ápice; os artículos, do primeiro ao último, com as seguintes medidas, em milímetros: 0,$36 ; 0,20 ; 0,40 ; 0,32 ; 0,28 ; 0,26 ; 0,26$; 0,$24 ; 0,22 ; 0,24 ; 0,40$. O pronoto quase duas vezes mais longo que sua largura mediana $(1,83 \times 3,67 \mathrm{~mm})$; margem anterior quase reta, margens laterais subparalelas, levemente arqueadas e posteriormente voltadas para dentro; margem da projeção mediana posterior quase reta; superfície do disco lisa e aos lados com grossos pontos (média de $0,08 \mathrm{~mm}$ de diâmetro); posteriormente, antes da projeção mediana, com suave sulco transversal. Escutelo subretangular; margens laterais levemente côncavas e margem posterior convexa. Élitros, pouco mais de duas vezes mais longos que sua maior largura; superfície com oito fileiras de pontos; os anteriores, em geral de diâmetro maior que os pontos médios ou posteriores; aos lados e próximo ao ápice os pontos são esparsos e em geral, a distância de um ponto a outro é maior que duas vezes seu diâmetro; margem anterior profundamente chanfrada; os cantos umerais, com um pequeno dente, quase alcançam a linha mediana e transversal do pronoto; margens laterais se alargam suavememte até a linha dos calos umerais e depois se estreitam suavemente para trás, até o ápice. Pernas com os fêmures de mesmo comprimento $(1,7 \mathrm{~mm})$; o diâmetro do fêmur posterior maior que o médio e este, do anterior $(0,72 ; 0,56 ; 0,52 \mathrm{~mm})$; tarsos enegrecidos dorsalmente. Abdômen com os dois esternos anteriores fundidos no meio, em conjunto, cerca de duas vezes mais largo que longo $(2,12 \times 4,00 \mathrm{~mm})$; o terceiro cerca de seis vezes mais largo que longo $(0,6 \times 3,6 \mathrm{~mm})$; o quarto pouco mais longo que o anterior e pouco mais estreito; o último, pouco mais longo que o anterior e no ápice, largamente arredondado.

Holótipo. Porto Platon, Amapá, 6-VII-1983. J.I. Lacerda leg. Parátipos: 3 exemplares com os mesmos dados do Holótipo. Depositados na Coleção de Entomologia Pe. Jesus Santiago Moure do Departamento de Zoologia da Universidade Federal do Paraná (DZUP).

\section{LARVA}

(Figs 5-6, 9-16). A larva, totalmente desenvolvida, com o corpo alongado, aproximadamente três vezes mais longo que sua maior largura (excluídos os escolos); dorso-ventralmente pouco achatada; os lados subparalelos, posteriormente pouco mais estreitada.

Aos lados com 13 pares de escolos, assim dispostos: pro-, meso-,e metatórax, com dois pares cada; tergos abdominais ( 1 a 7 ) com um par cada. Os dois mais anteriores, fixos aos lados do pronoto; o mais anterior, com 1,5mm de comprimento, cônico, voltado para fora e levemente curvado para trás; na base de diâmetro bem maior que os cinco seguintes; o segundo, fixo mais atrás, aos lados do pronoto, com cerca de um milímetro de comprimento, voltado para fora, cônico; o terceiro e quarto pares, aos lados do mesotórax, voltados levemente para baixo, mais fortemente o anterior, que é também um pouco mais curto; o quinto e sexto pares, semelhantes aos anteriores ( $3^{\circ}$ e $\left.4^{\circ}\right)$; sétimo, oitavo e nono pares, subiguais no comprimento; $10^{\circ}, 11^{\circ}$ e $12^{\circ}$ pares, subiguais em comprimento porém pouco mais curtos que os anteriores; na base, engrossados 
e depois diminuindo rapidamente de diâmetro; a relação entre a porção de maior e a de menor diâmetro, vai diminuindo para trás; sétimo e oitavo pares, voltados para fora e os demais, na porção distal, voltados levemente para frente. O $13^{\circ}$ par, cerca de duas vezes mais longo que o anterior, com quase dois milímetros de comprimento; voltado para fora e muito fracamente para trás; cônico, com a base bastante engrossada. Superfície dos escolos, do primeiro ao sexto par, com curtos processos espiniformes (Fig. 12) que também estão presentes no ápice dos demais escolos.

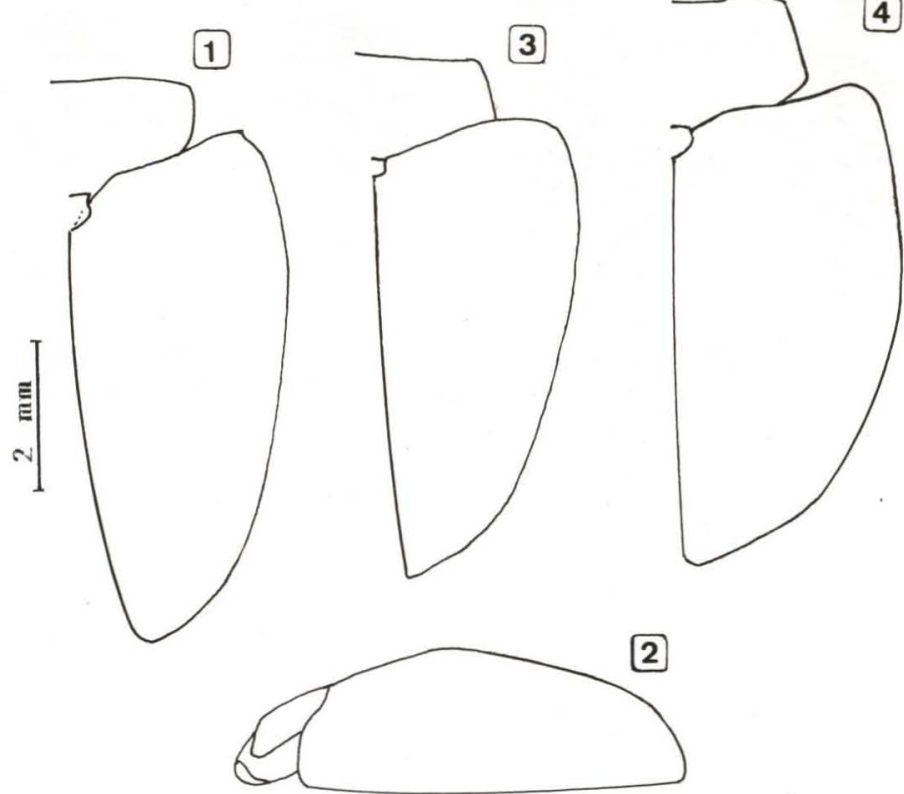

Figs 1-4. Calyptocephala paralutea, sp.n. (1) Vista dorsal; (2) vista de perfil; (3) C. lutea; (4) C. punctata. Figuras 3 e 4 desenhadas a partir de diapositivos de exemplares da Coleção do "The Natural History Museum".

Cabeça (Fig.9) com epicrânio cerca de 1,5 vezes mais largo que longo com seis ocelos, dispostos em três pares: um no lado externo e dois atrás das antenas. Estas uniarticuladas, tendo no ápice vários processos sensoriais, destacando-se um, maior. Clípeo sub-retangular, aproximadamente cinco vezes mais largo que longo; margem anterior levemente convexa. Labro, pouco mais de duas vezes mais largo que seu comprimento mediano; margem anterior levemente chanfrada; os lados convergindo para frente. Mandíbulas (Fig. 13) mais de 1,5 vezes mais longas que sua base; fortemente estreitada para o ápice, onde estão quatro dentes, um mais saliente; no lado externo fortemente abaulada; lado interno, com forte concavidade, no sentido do comprimento. Maxilas (Fig. 10) alongadas; cardo subretangular; estipe dividida em duas partes separadas por depressão transversal; palpo maxilar biarticulado; lacínea e gálea 

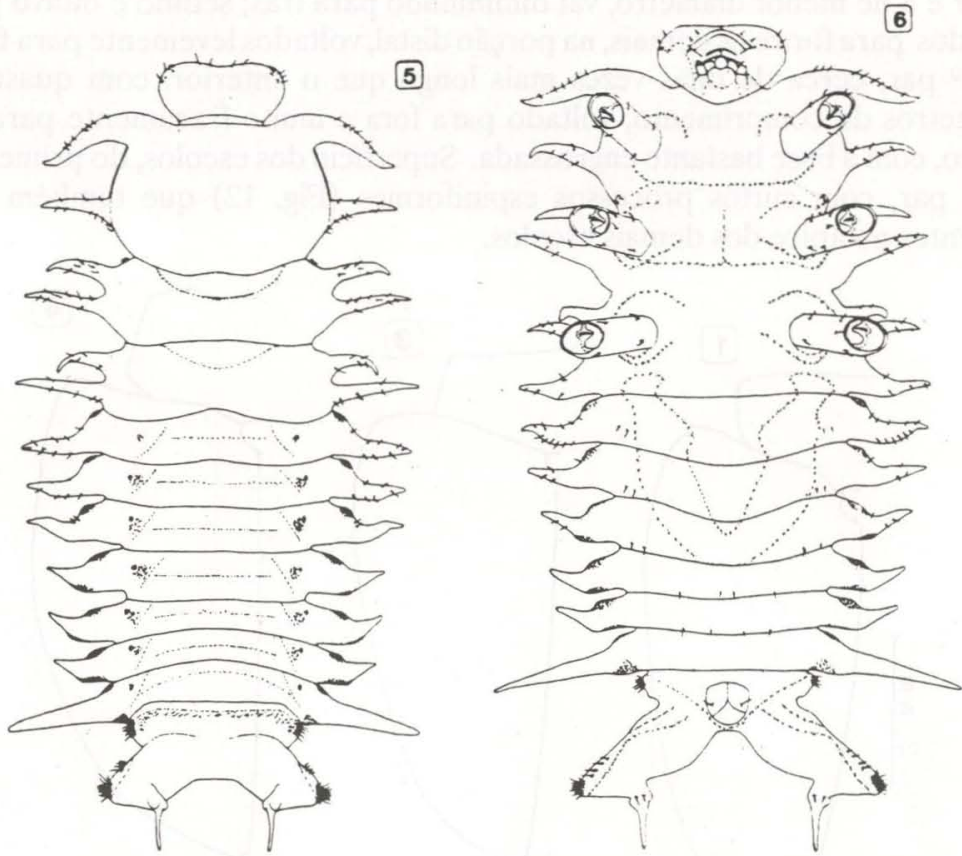

7
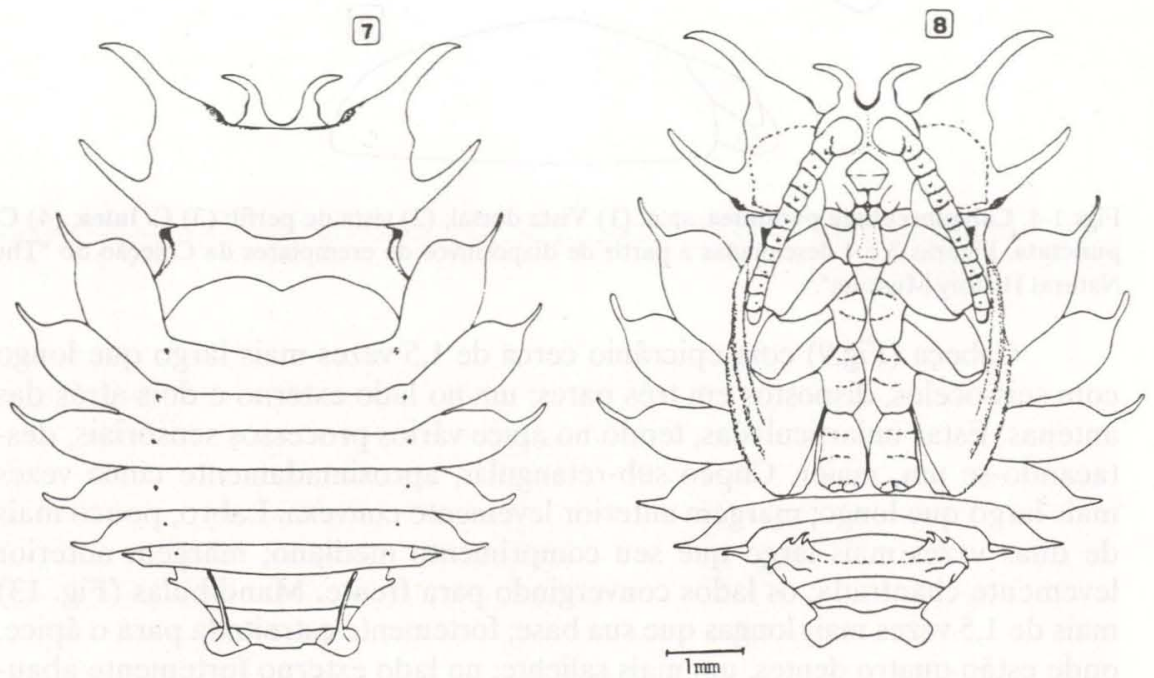

Figs 5-8. Calyptocephala paralutea sp.n. Larva. (5) Vista dorsal; (6) Vista ventral. Pupa. (7) Vista dorsal; (8) vista ventral.

Revta bras. Zool. 9 (1/2): 157-166, 1992 
globosos. Lábio com área do mento e submento fundidas e alargadas para trás; estipe bem saliente com palpo labial uniarticulado e subcônico, com vários e curtos processos sensoriais no ápice.

Pronoto aproximadamente 1,5 vezes mais largo que seu comprimento mediano; superfície, aos lados, revestida com minúsculos processos espiniformes que lhe dá aspecto áspero; aos lados, dorsalmente, com suave e larga depressão. Meso- e metanoto semelhantes, aproximadamente 3,5 vezes mais largos que seu comprimento mediano; na metade anterior com sulco em arco que delimita área levemente abaulada. Látero-anteriormente ao mesotórax, próximo à base do terceiro par de escolos, o espiráculo mesotorácico, com peritrema pouco saliente.

Tergos abdominais, curtos e bastante alargados; para trás, estreitados; um a sete, divididos por sulco transversal em pré- e postergitos. $O$ último tergo $\left(8^{\circ}\right)$, com faixa transversal saliente, na sua porção mais dorsal, com processos espiniformes e quitinosos escuros, curtos e cônicos, formando estreita faixa transversal, os mais externos mais robustos; processos semelhantes, formando manchas subarredondadas bem evidentes, estão próximo ao lado interno dos espiráculos do segundo ao sexto segmento abdominal (Fig. 11).

Ao lado dos tergos abdominais, oito pares de espiráculos, um par por tergo, formando uma linha próxima à base dos escolos, com peritrema saliente, diminuindo de tamanho dos anteriores para os posteriores; o oitavo, situado látero-anteriormente na base da furca anal.

Pernas subiguais. Coxa com a porção esclerotinizada em forma de "V" aberto e ramos alargados; trocânter curto; fêmur subcilíndrico, robusto, aproximadamente duas vezes mais longo que seu maior diâmetro; tíbia subcônica, muito curta, seu diâmetro basal quase duas vezes seu comprimento; no lado ventral, com formação laminar, ímpar, pulviliforme e profundamente chanfrada; tarsúngulo forte, com a porção presa à tíbia, maior que a porção livre (Fig. 14).

Esternos abdominais curtos, largos e levemente estreitados para trás; no último, a abertura anal.

Furca anal com cada um de seus ramos divididos em duas partes: a basal, robusta, diminuindo de diâmetro em direção ao ápice, com aproximadamente dois milímetros de comprimento, externamente com sulco longitudinal; a parte apical, mais delgada, da metade do comprimento da basal e onde se prendem as exúvias das mudas, em seqüência, sem excrementos, que a larva carrega e ficam voltadas dorsalmente, para frente, e na fase pupal ficam sobre a pupa (Fig. 15 e 16).

Pilosidade. Cabeça com cerdas dorsais posteriores no epicrânio e algumas, anteriores dorsais e ventrais. No clípeo destacam-se quatro cerdas, duas a cada lado. Labro com várias cerdas de tamanhos diversos; próximo à margem anterior com estreita faixa de numerosas e curtas cerdas. Maxilas e lábio com várias cerdas, sendo mais numerosas na lacínea e gálea. Mandíbula com duas cerdas na face externa. 

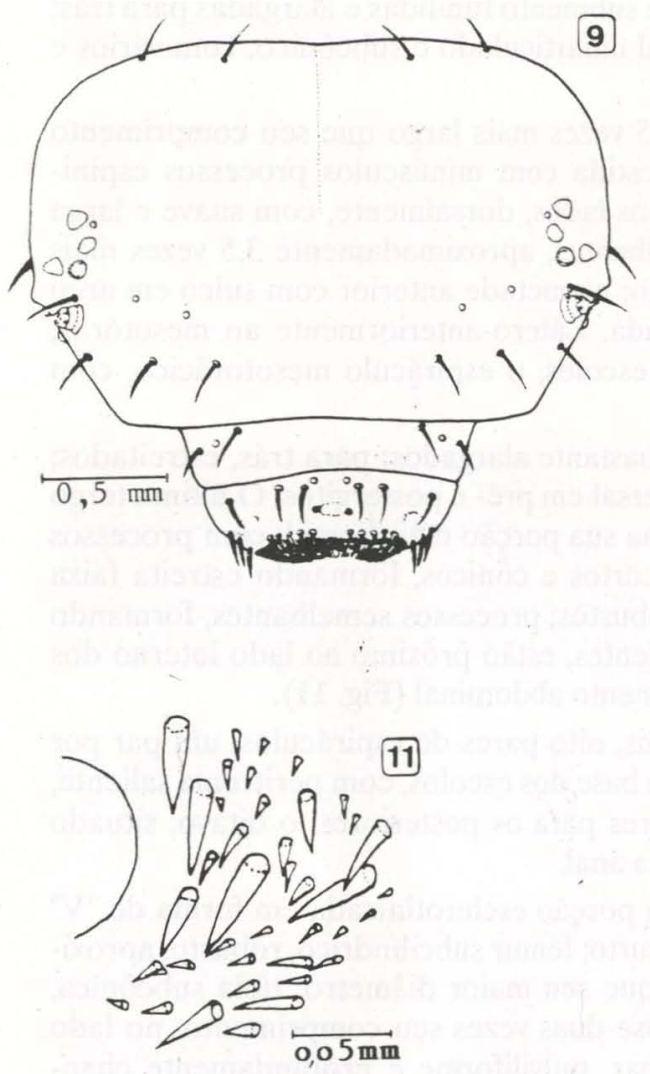

11
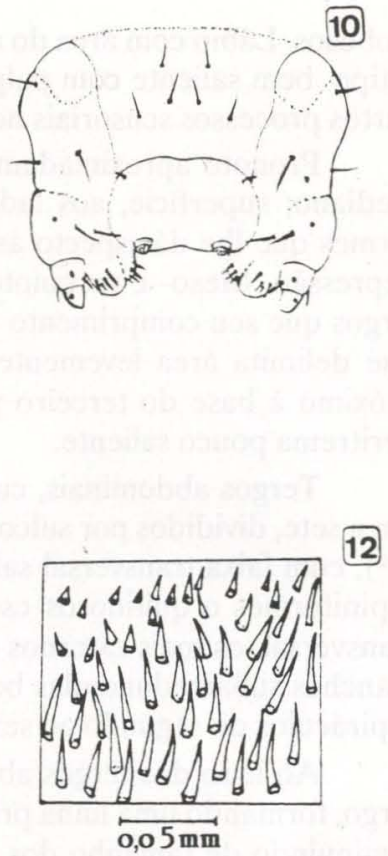

13
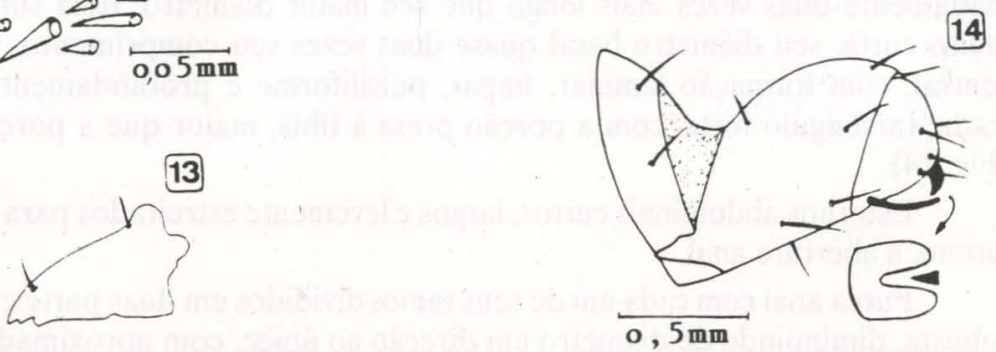

Figs 9-14. Calyptocephala paralutea, sp.n. (9) Cabeça; (10) lábio e maxilas; (11) processos quitinosos próximos ao $6^{\circ}$ espiráculo abdominal; (13) Mandibula; (14) perna anterior da larva.

Corpo recoberto por cerdas esparsas e curtas, diretamente fixas no tegumento ou sobre curtos processos cuticulares, como nos escolos. Aos lados do pronoto e na base dos escolos abdominais ou próximo, com cerdas densas e eretas. Nos esternos abdominais um a quatro, com cerdas curtas e densas, piliformes; no meio dos esternos um a três, com área glabra, maior no anterior e que em conjunto tem aspecto de "U". Cerdas das pernas, maiores e eretas. No lado externo e subapical da porção basal dos ramos da furca anal, com tufo de cerdas. 
Coloração.Tegumento amarelo. Ápice dos escolos geralmente enegrecidos. Entre os escolos 3-4 e 5-6, na base, com mancha escura e sub- arredondada (Fig. 15). Pronoto com algumas manchas escuras, de contorno não definidos.
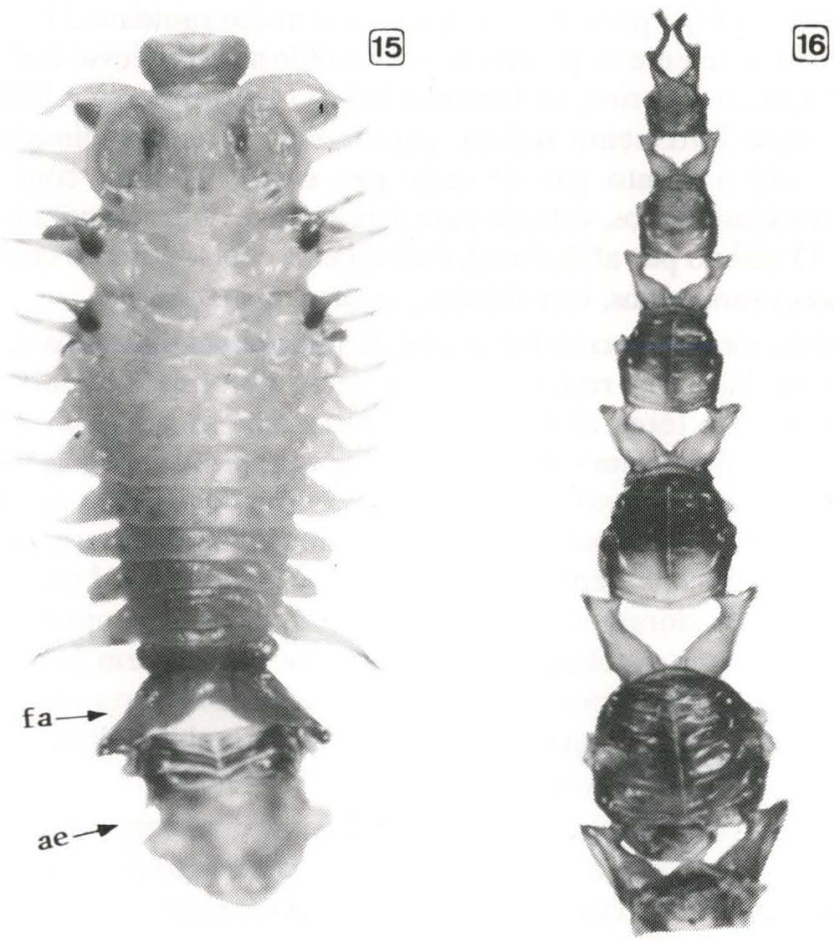

Figs 15-16. Calyptocephala paralutea, sp.n. (15) Larva em vista dorsal, tendo na parte posterior o anexo exuvial (ae) preso à furca anal (fa); (16) anexo exuvial, mostrando as exúvias de $1^{\mathbf{a}}$ a $5^{\mathbf{a}}$ muda.

PUPA

(Figs. 7-8). Corpo alongado, aproximadamente duas vezes mais longo que sua maior largura (excluídos os escolos); dorso-ventralmente pouco achatada; lado dorsal levemente convexo e no lado ventral, aplanada. Superfície quase toda recoberta com processos microscópicos, muito próximos uns dos outros, subcônicos, o que lhe dá aspecto áspero. Nos élitros, destacam-se três faixas escuras longitudinais, equidistantes e subparalelas à margem posterior, onde se situa uma faixa e que alcança o ápicę; a faixa anterior origina-se no calo umeral, bastante saliente e apaga-se antes de alcançar a margem; a faixa intermediária inicia atrás do calo umeral e termina próximo ao ápice. Aos lados e anteriormente com 10 pares de escolos, assim dispostos: um cefálico, dois pronotais e sete abdominais. $\mathrm{O}$ par mais anterior, com aproximadamente $0,92 \mathrm{~mm}$ de comprimento, no vértice da cabeça, subcônico, voltado para frente e encurvado para fora; o segundo e terceiro pares de escolos, no pronoto; o 
segundo látero-anterior, subcônico, recurvado para cima, com 1,68mm de comprimento; o terceiro, com $1,3 \mathrm{~mm}$ de comprimento, voltado para fora e fracamente para frente, pouco recurvado para cima e subcônico. Os demais escolos, aos lados dos tergos abdominais um a sete: os cinco anteriores, com aspecto foliar, translúcidos e próximos ao ápice, estreitados rapidamente no lado anterior e mais suavemente no posterior, terminando num processo cônico alongado e espiniforme; o anterior, de tamanho maior (comprimento e largura) que os demais e mais fortemente voltado para frente; os demais diminuindo gradativamente até o quinto par. O sexto par, curto $(0,5 \mathrm{~mm})$, cônico; num dos exemplares examinados, voltado para fora e outro, dobrado para trás, na altura do meio. O sétimo par abdominal, com escolos cônicos, muito curtos, num dos exemplares examinados, com $0,6 \mathrm{~mm}$ e noutro, com $0,2 \mathrm{~mm}$.

Posteriormente, com furca anal de ramos bem afastados um do outro e dilatados na base; no restante, com aspecto filiforme; voltados para frente alcançam o sexto tergo abdominal. $\mathrm{Na}$ furca anal se prendem as exúvias das ecdises larvais, que ficam sobre a pupa. Cabeça sulcada ao longo do meio, mais fortemente na área interalveolar. No lado externo da base das antenas, os olhos compostos alongados e pouco evidentes. Antenas voltadas para trás e para fora, alcançando o ápice do fêmur anterior; cada artículo antenal com três nódulos, um interno, um dorsal e um externo, formando em conjunto, três fileiras longitudinais. Área do clípeo e labro bastante saliente, em forma de losango; margem anterior levemente côncava e aos lados com curta projeção globosa. Mandíbulas bastante alongadas; margem interna rombuda. Palpos maxilares de diâmetro bem maior e mais longos que os palpos labiais.

Pronoto subretangular, aproximadamente duas vezes mais largo que seu comprimento mediano; ao longo do meio sulcado; margem anterior com largo chanfro e a posterior, largamente curvada, destacando-se a projeção mediana larga e pouco saliente.

Mesonoto cerca de quatro vezes mais largo que seu comprimento mediano; margem posterior, projetada para trás no meio; área do escutelo saliente e aos lados, com fraca depressão; látero-anteriormente, na base dos élitros, com projeção curta e globosa.

Élitros voltados para trás e ventralmente alcançam a linha do $4^{\circ}-5^{\circ}$ pares de escolos abdominais e escondem a perna posterior com exceção dos tarsos.

Metanoto, no meio mais longo que o mesonoto e com suave sulco longitudinal; margem posterior em forma de "V" aberto.

Tergos abdominais curtos e largos; aos lados dos tergos um a seis, os espiráculos, um par por segmento; o anterior, com peritrema muito saliente e nos demais diminuindo gradativamente para trás.

Entre as coxas anteriores transversais, nota-se o processo prosternal que é mais largo no ápice e ao longo do meio, com forte sulco. Perna anterior com trocânter subtriangular, com pequena projeção posterior; fêmur achatado, cerca de 2,5 vezes mais longo que largo; tíbia tão longa quanto o fêmur. A perna média com fêmur e tíbia de mesmo aspecto que da perna anterior. Tarsômeros 
mais ou menos evidentes.

Esternos abdominais visíveis, curtos e bastante largos. Aos lados do esterno correspondente ao sétimo par de escolos abdominais, com processo laminar voltado para fora e com várias projeções espiniformes (em torno de cinco).

Coloração. Corpo castanho: dorsalmente mais escuro, com pequenas e fracas manchas arredondadas no lado interno da linha dos espiráculos; o lado ventral, de coloração mais clara e uniforme, exceto os élitros, com faixas de processos mais escuras.

\section{DISCUSSÃO}

Calyptocephala paralutea, sp.n. muito próxima de C. lutea Boheman, 1850 (Fig. 3) da qual se distingue pela coloração mais clara, as margens dos élitros, a partir da linha dos calos umerais, para trás, não se estreitam tão rapidamente e as margens laterais do pronoto, posteriormente, estão voltadas para dentro; de C.brevicornis Boheman, 1850 se distingue pela coloração mais parda e pela pontuação dos élitros; de C. nigricornis (Germar, 1824) se distingue pelas antenas mais grossas e também pela coloração; de C. punctata Boheman, 1850 se distingue pelo formato do ápice do escutelo fortemente convexo, pelo chanfro mais largo e mais pronunciado da margem anterior do pronoto e pelo formato dos élitros (Fig. 4).

C. paralutea, sp.n. mede $8,33 \times 5,67 \mathrm{~mm}$ e segundo BOHEMAN (1850) C. lutea mede $9 \times 6,5 \mathrm{~mm} ; C$. punctata, $5 \times 4,5 \mathrm{~mm}$; $C$. nigricornis, $9,5 \times 8 \mathrm{~mm}$ e $C$. brevicornis, $7,75 \times 5,5 \mathrm{~mm}$.

O Sr. J.I. Lacerda Moura constatou que C. paralutea, sp.n. ataca cultura de dendê (Elaeis guineensis) e que também vive sobre uma palmeira nativa do gênero Astrocaryum, vulgarmente conhecida como "mumbaca".

A larva e pupa de C. paralutea, sp.n. facilmente se distinguem dos imaturos de Himatidium neivai Bondar, 1940 (Himatidini), descritos por BONDAR (1940a, b, c, d); de Delocrania cossyphoides Guérin, 1844 (Delocraniini) descritos por BONDAR (1940a) e GENTY et al., 1978a e de Spaethiella tristis (Boheman, 1850) (Hemisphaerotini) descritos por OLLIFF (1884), BONDAR (1940a) e GENTY et al. (1978b); a larva pelo número, tamanho e forma dos escolos torácicos e abdominais, pelo aspecto da furca anal e pelo formato do anexo exuvial; a pupa principalmente pelo número, forma e tamanho dos escolos cefálicos, torácicos e abdominais, forma da furca anal e processo prosternal.

\section{REFERÊNCIAS BIBLIOGRÁFICAS}

BLACKWELDER, R.E. 1946. Checklist of the the Coleopterous insects of Mexico, Central America, the West Indies and South America. Smithsonian Institution. Bull. U. S. Nat. Mus. 185 (4): 551-763.

BOHEMAN, C.H. 1850. Monographia Cassididarum. Tomus Primus. Holmiae, ex Officina Nortedtiana, 452p. 
BONDAR, G. 1940a. Insetos nocivos e moléstias do coqueiro (Cocus nucifera) do Brasil. Bol. Inst. Fom. econ., Bahia, 8: 1-160.

- 1940b. Crisomelídeos nocivos ao coqueiro. Gênero Himatidium. O Campo 11 (125): 12-13.

—. 1940c. Notas entomológicas da Bahia V. Revta Ent. 11 (1-2): 199-214.

. 1940d. Notas entomológicas da Bahia VI. Revta Ent. 11 (3): 843-862.

GENTY, P.; R. DESMIER DE CHENON \& J.P. MORIN. 1978a. Delocrania cossyphoides Guérin. (Chrysomelidae, Cassidinae). Oleagineux 33 (7): 327-328.

- 1978b. Spaethiella tristis Boh. (Chrysomelidae, Cassidinae). Oleagineaux 33 (7): 329-330.

HINCKS, W.D. 1952. The genera of the Cassidinae (Coleoptera, Chrysomelidae). Trans. R. Ent. Soc. Lond. 103 (10): 327-358.

MOURA, J.I.L. 1985. Incidência de Calyptocephala brevicornis (Boheman,1850)(Coleoptera, Chrysomelidae, Cassidinae) em cultura de dendê (Elaeis guineensis) no Município de Porto Platon, Território Federal do Amapá. An.Soc.Entomol.Brasil 14 (1): 37-43.

OLLIFF, S.A. 1884. Notes on the life-history of Porphyraspis tristis a palminfesting Cassida, from Brazil. Trans. R. Ent. Soc. Lond. Part III (Oct.): 435-437.

SPAETH, F. 1937. Mitteilungen über Cassidinen mit besonderer Berücksichtigung der Sammlung des Naturkundemuseums der Stadt Stettin. (Col.). Stett. ent. Ztg. 98 (1): 79-95.

Recebido em 02.XI.1992; aceito em 07.VI.1993. 